\title{
Rac Regulates the TRAP-Induced Release of Phosphorylated-HSP27 from Human Platelets via p38 MAP Kinase but Not JNK
}

\author{
Kodai Uematsu ${ }^{\mathrm{a}, \mathrm{b}} \quad$ Yukiko Enomoto ${ }^{\mathrm{a}}$ Takashi Onumab,d Masanori Tsujimoto ${ }^{\mathrm{a}}$ \\ Tomoaki Doic Rie Matsushima-Nishiwakib Haruhiko Tokudab,e Shinji Ogurac

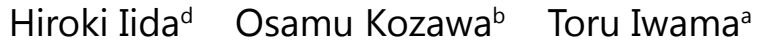

${ }^{a}$ Department of Neurosurgery, Gifu University Graduate School of Medicine, Gifu, bDepartment of Pharmacology, Gifu University Graduate School of Medicine, Gifu, 'Department of Emergency and Disaster Medicine, Gifu University Graduate School of Medicine, Gifu, dDepartment of Anesthesiology and Pain Medicine, Gifu University Graduate School of Medicine, Gifu, eDepartment of Clinical Laboratory/Medical Genome Center Biobank, National Center for Geriatrics and Gerontology, Obu, Aichi, Japan

\section{Key Words}

Platelet - Rac • p38 MAP kinase - JNK - Protease-activated receptor - Thrombin receptoractivating peptide $\cdot$ Heat shock protein $27 \cdot$ Phosphorylation

\begin{abstract}
Background/Aims: Thrombin induces the activation of human platelets through proteaseactivated receptor (PAR) 1 and PAR4, and Rac, a member of the Rho family of small GTPases, is implicated in PAR activation. We previously reported that phosphorylated-heat shock protein 27 (HSP27) is released from the thrombin receptor-activating peptide (TRAP)-stimulated platelets of diabetic patients. In the present study, we investigated the role of Rac in the TRAP-elicited release of phosphorylated-HSP27 from human platelets. Methods: Platelet aggregation was measured using an aggregometer with laser scattering. Protein phosphorylation was analyzed by Western blotting. The levels of phosphorylated-HSP27 and platelet-derived growth factorAB (PDGF-AB) were measured by enzyme-linked immunosorbent assays. Results: NSC23766, an inhibitor of Rac-guanine nucleotide exchange factor interaction, suppressed the TRAPelicited release of phosphorylated-HSP27 as well as platelet aggregation. The TRAPinduced phosphorylation of HSP27, p38 mitogen-activated protein kinase (MAPK) and c-Jun $\mathrm{N}$-terminal kinase (JNK) was attenuated by NSC23766. SB203580, a p38 MAPK inhibitor, but not SP600125, a JNK inhibitor, suppressed the release of phosphorylated-HSP27 in addition to HSP27 phosphorylation. On the other hand, both SB203580 and SP600125 reduced the TRAP-stimulated secretion of PDGF-AB. Conclusion: Our results strongly suggest that Rac acts as a positive regulator of the PAR-elicited release of phosphorylated-HSP27 from human platelets via p38 MAPK but not JNK.




\section{Cellular Physiology Cell Physiol Biochem 2018;49:1523-1538 and Biochemistry Published online: 13 September, 2018 \begin{tabular}{l|l} 
DOI: 10.1159/000493456 & $\begin{array}{l}\text { (c) } 2018 \text { The Author(s). Published by S. Karger AG, Basel } \\
\text { www.karger.com/cpb }\end{array}$
\end{tabular} \\ Uematsu et al.: Rac Regulates the Release of Phospho-HSP27}

\section{Introduction}

It is widely accepted that Rac is a member of the Rho family of small GTPases and functions as a so-called "switch" of its downstream signaling pathway [1]. Rac is inactive when bound to GDP. Through its interaction with a guanine nucleotide exchange factor (GEF), which generates GTP-binding Rac, an active form by exchanging GDP with GTP, activated Rac can transmit signals to its downstream effectors $[1,2]$. It is generally recognized that Rac is ubiquitously expressed in various cells and regulates the reorganization of the actin cytoskeleton [1, 3-5].

Human platelets play crucial roles in not only hemostasis but also pathological thrombus formation. It is firmly established that thrombin, a serine protease, is a direct activator of human platelets in addition to its role as a coagulation factor [6]. At the site of an injured vessel, exposed tissue factor initiates the coagulation cascade, resulting in the generation of thrombin from prothrombin [6]. Thrombin binds to protease-activated receptors (PARs) expressed on the membrane of platelets and cleaves the amino-terminal exodomain to unmask a new amino terminus. This new amino terminus then serves as a tethered ligand and activates PARs, leading to platelet activation [7]. PARs belong to the GTP-binding proteincoupled receptor superfamily, and PAR1 and PAR4 among PARs are expressed on human platelets [8]. Thrombin receptor-activating peptide (TRAP), consisting of an identical amino acid sequence to the tethered ligand of PARs cleaved by thrombin, is a useful tool to evaluate the function of PARs [9]. Accompanying platelet activation, many different mediators including ADP, serotonin and thromboxane $\mathrm{A}_{2}\left(\mathrm{TXA}_{2}\right)$ are released from platelets [6]. These agents amplify human platelets as autacoids, leading to thrombus formation [6]. Regarding Rac in human platelets, it has recently been reported that Rac is implicated in platelet aggregation, the activation of $\alpha_{\mathrm{IIb}} \beta_{3}$ or phospholipase $C$, and granule secretion [10-13]. In our previous report [14], we showed that Rac acts as a positive regulator of the release of soluble CD40 ligand (sCD40L) and the secretion of platelet-derived growth factor-AB (PDGF$\mathrm{AB}$ ) induced by TXA from human platelets. Regarding the relationship between PARs and Rac in human platelets, it has been reported that Rac is activated by PAR stimulation $[15,16]$. However, the exact roles of Rac behind the PAR-mediating signaling in human platelets have not yet been clarified.

The expression of heat shock proteins (HSPs) is induced in response to various environmental stresses including chemical, metabolic and pathophysiological stresses while some HSPs are constitutively expressed $[17,18]$. It is generally recognized that HSPs act intracellularly as molecular chaperones and facilitate the refolding of damaged proteins [17, 18]. Among HSPs, low-molecular weight HSPs with a molecular weight of $13-43 \mathrm{kDa}$ are currently classified into the HSPB family $[18,19]$. HSP27, a member of the HSPB family, is constitutively expressed in a variety of cells including human platelets $[18,19]$. It is well established that human HSP27 is phosphorylated at three serine residues (Ser-15, Ser-78 and Ser-82) as one of post-translational modifications $[19,20]$. Although HSP27 exists in an unphosphorylated aggregated form, phosphorylated-HSP27 transforms into a dimer or monomer, resulting in the modulation of its chaperone activity [17, 21-23]. Accumulating evidence indicates that HSP27 is involved in the development of cancer, cardiovascular events and inflammatory responses in addition to its function as a molecular chaperone [21, 24-26]. In addition to its intracellular roles, it has recently been reported that HSP27 plays an extracellular role as a regulator of inflammation [27]. Regarding HSP27 in human platelets, we have reported that ADP- or collagen-induced HSP27 phosphorylation is mediated through p44/p42 mitogen-activated protein kinase (MAPK), and HSP27 phosphorylation is accompanied with both the secretion of PDGF-AB and the release of SCD40L $[28,29]$. In addition, we showed that Rac positively regulates collagen-induced HSP27 phosphorylation via p44/p42 MAPK [30]. Moreover, in our recent studies [31, 32], we demonstrated that phosphorylated-HSP27 is released from platelets stimulated by collagen or TRAP in diabetic 


\section{Cellular Physiology Cell Physiol Biochem 2018;49:1523-1538 \begin{tabular}{l|l} 
DOI: 10.1159/000493456 & $\begin{array}{l}\text { O } 2018 \text { The Author(s). Published by S. Karger AG, Basel } \\
\text { www.karger.com/cpb }\end{array}$
\end{tabular}}

patients. However, the exact mechanism underlying the release of phosphorylated-HSP27 from human platelets remains unclear.

In this study, we investigated the role of Rac in PAR-induced human platelet activation, particularly in the release of phosphorylated-HSP27 compared with PDGF-AB secretion. We herein show that Rac positively regulates the TRAP-induced phosphorylation of HSP27 at a point upstream of p38 MAPK in human platelets, resulting in the release of phosphorylatedHSP27.

\section{Materials and Methods}

\section{Materials}

TRAP (H-Ser-Phe-Leu-Leu-Arg-Asn-Pro-Asn-Asp-Lys-Tyr-Glu-Pro-Phe-OH trifluoroacetate salt) was purchased from Bachem (Bubendorf, Switzerland). NSC23766 was obtained from Tocris Bioscience (Bristol, UK). SCP0237 and A3227 were purchased from Sigma-Aldrich (St. Louis, MO). SB203580 and SP600125 were purchased from Calbiochem-Novabiochem Co. (La Jolla, CA). Phospho-specific HSP27 (Ser78) antibodies were obtained from Enzo Life Sciences, Inc. (Farmingdale, NY). Phospho-specific p38 MAPK antibodies, p38 MAPK antibodies, phospho-specific p44/p42 MAPK antibodies, p44/p42 MAPK antibodies, phospho-specific c-Jun N-terminal kinase (JNK) antibodies, JNK antibodies, phospho-specific Akt antibodies and Akt antibodies were purchased from Cell Signaling Technology (Danvers, MA). GAPDH antibodies and HSP27 antibodies were purchased from Santa Cruz Biotechnology, Inc. (Santa Cruz, CA). A PDGF-AB enzyme-linked immunosorbent assay (ELISA) kit was obtained from R\&D Systems, Inc. (Minneapolis, MN). A phosphorylated-HSP27 (Ser-78) ELISA kit was purchased from Enzo Life Sciences, Inc. (Farmingdale, NY). A Rac1 Activation Assay Kit was purchased from Millipore Co. (Billerica, MA). Other materials and chemicals were obtained from commercial sources. SCP0237, SB203580 and SP600125 were dissolved in dimethyl sulfoxide. The maximum concentration of dimethyl sulfoxide was $0.3 \%$, which did not affect platelet aggregation, Western blotting or ELISAs for phosphorylated-HSP27 and PDGF-AB.

\section{Preparation of platelets}

Human blood was donated from healthy volunteers into a $1 / 10$ volume of $3.8 \%$ sodium citrate. Plateletrich plasma (PRP) was obtained from blood samples by centrifugation at $155 \times g$ at room temperature for 12 min. Platelet-poor plasma (PPP) was obtained from the residual samples by centrifugation at 1,400 $\times g$ at room temperature for 5 min. This study was approved by the Ethics Committee of Gifu University Graduate School of Medicine (Gifu, Japan). All participants signed an informed consent agreement after receiving an explanation of the study.

\section{Platelet aggregation}

Platelet aggregation was analyzed using a PA-200 aggregometer (Kowa Co., Ltd., Tokyo, Japan), which can determine the size of platelet aggregates based upon particle counting by a laser scattering method (small size, 9-25 $\mu \mathrm{m}$; medium size, 25-50 $\mu \mathrm{m}$; and large size, 50-70 $\mu \mathrm{m}$ ). PRP was preincubated at $37^{\circ} \mathrm{C}$ for $1 \mathrm{~min}$ at a stirring speed at $800 \mathrm{rpm}$. When indicated, PRP was pretreated with NSC23766, SB203580 or SP600125 for $15 \mathrm{~min}$, and then stimulated by TRAP, SCP0237 or A3227. The dose of stimulants achieving a transmittance of $80-100 \%$ recorded by the aggregometer was adjusted individually. Platelet aggregation was monitored for $4 \mathrm{~min}$. The percentage of transmittance of the isolated platelets was recorded as $0 \%$, and that of the appropriate PPP was recorded as $100 \%$.

\section{Protein preparation after stimulation}

After stimulation by TRAP, SCP0237 or A3227, platelet aggregation was terminated by the addition of an ice-cold EDTA $(10 \mathrm{mM})$ solution. The conditioned mixture was centrifuged at $10,000 \times g$ at $4^{\circ} \mathrm{C}$ for 2 $\mathrm{min}$. The supernatant was isolated for ELISA and stored at $-80^{\circ} \mathrm{C}$ until measurement. The pellet was washed twice with phosphate-buffered saline (PBS), then lysed by boiling in a lysis buffer [62.5 mM Tris- $\mathrm{HCl}, \mathrm{pH}$ $6.8,2 \%$ sodium dodecyl sulfate (SDS), $50 \mathrm{mM}$ dithiothreitol and $10 \%$ glycerol] for a Western blot analysis. 


\section{Cellular Physiology Cell Physiol Biochem 2018;49:1523-1538 \begin{tabular}{ll|l} 
and Biochemistry Published online: 13 September, 2018 & $\begin{array}{l}\text { (c) } 2018 \text { The Author(s). Published by S. Karger AG, Basel } \\
\text { www.karger.com/cpb }\end{array}$ \\
\hline
\end{tabular}}

\section{Western blot analysis}

Western blot analysis was performed as described previously [31]. Briefly, SDS-polyacrylamide gel electrophoresis (PAGE) was performed according to the method of Laemmli in $10 \%$ or $12.5 \%$ polyacrylamide gels [33]. The proteins in the gel were transferred onto a polyvinylidene fluoride (PVDF) membrane and blocked with 5\% fat-free dry milk in PBS containing 0.1\% Tween 20 (PBS-T; $10 \mathrm{mM} \mathrm{Na} \mathrm{HPO}_{4}, 1.8 \mathrm{mM}$ $\mathrm{KH}_{2} \mathrm{PO}_{4}, \mathrm{pH} 7.4,137 \mathrm{mM} \mathrm{NaCl}, 2.7 \mathrm{mM} \mathrm{KCl}$ and $0.1 \%$ Tween 20) for $2 \mathrm{~h}$, and then incubated with the indicated primary antibodies. Peroxidase-labeled anti-rabbit IgG antibodies, anti-goat IgG antibodies or anti-mouse IgG antibodies were used as secondary antibodies. Primary and secondary antibodies were diluted to optimal concentration with 5\% fat-free dry milk in PBS-T. Peroxidase activity on the PVDF membrane was visualized on X-ray film using an ECL Western blot detection system (GE Healthcare, Buckinghamshire, UK) as described in the manufacturer's protocol. Densitometric analysis was performed using a scanner and imaging software (Image J version 1.50; NIH, Bethesda, MD). The data of Western blot analysis presented in each figure are representative results from different individuals pooled. Phosphorylation levels were calculated as follows: the background-subtracted intensity of each signal was normalized to the respective intensity of GAPDH or total protein, and plotted as a fold increase compared with that of control cells without stimulation.

\section{Measurement of phosphorylated-HSP27 and PDGF-AB}

The levels of phosphorylated-HSP27 and PDGF-AB in the supernatant of the conditioned mixture after platelet aggregation were determined using ELISA kits for phosphorylated-HSP27 and PDGF-AB in accordance with the manufacturer's instructions.

\section{Analysis of Rac activation}

PRP was stimulated by TRAP for the indicated periods, and the reaction was terminated by the addition of an ice-cold EDTA (10 mM) solution. The conditioned mixture was then centrifuged at $10,000 \times g$ at $4^{\circ} \mathrm{C}$ for $2 \mathrm{~min}$, and the pellet was washed twice with ice-cold PBS. GTP-binding Rac was immunoprecipitated using a Rac1 Activation Assay Kit as described in the manufacturer's instruction manual. The immunoprecipitated GTP-binding Rac and pre-immunoprecipitated lysates, that is, total Rac, were subjected to Western blot analysis using antibodies against Rac and GAPDH.

\section{Statistical analysis}

The data were analyzed by the Mann-Whitney $U$ test with JMP version 13.0.0 (SAS Institute, Inc., Cary, NC). A probability of less than $5 \%$ was considered to be statistically significant. Data are presented as the mean \pm standard error of the mean (SEM).

\section{Results}

Effects of NSC23766 on human platelet aggregation induced by SCP0237 or A3227

It has been reported that Rac is activated by PAR stimulation in human platelets [15, 16], and PAR1 and PAR4 among PARs are present on the membrane of human platelets [7]. We confirmed that NSC23766, a selective inhibitor of Rac1-GEF interaction [2], markedly inhibited platelet aggregation induced by SCP0237, a selective PAR1 agonist [34] (Fig. 1). Similarly, NSC23766 suppressed platelet aggregation induced by A3227, a selective PAR4 agonist [35] (Fig. 1). According to an analysis of the size of the platelet aggregates by laser scattering, NSC23766 reduced the number of large aggregates stimulated by SCP0237 or A3227 but increased that of small aggregates (Table 1). Regarding TRAP-induced Rac activation in human platelets, we found that TRAP truly increased the levels of GTP-binding Rac, and NSC23766 inhibited the TRAP-induced platelet aggregation (data not shown). 


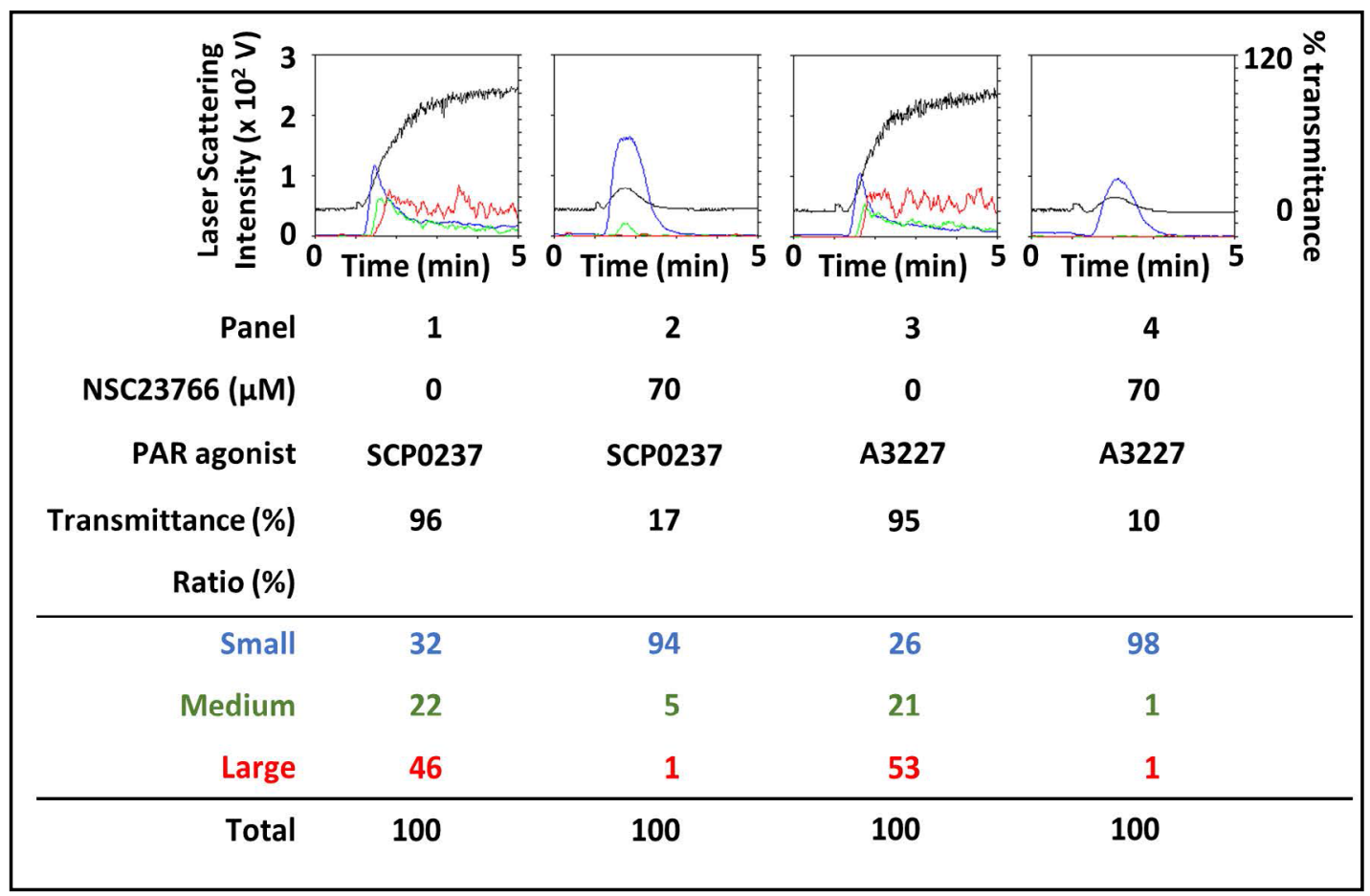

Fig. 1. Effects of NSC23766 on human platelet aggregation induced by SCP0237 and A3227. PRP was pretreated with $70 \mu \mathrm{M}$ of NSC23766 or vehicle at $37^{\circ} \mathrm{C}$ for $15 \mathrm{~min}$, and then stimulated by $7 \mu \mathrm{M}$ of SCP0237, $70 \mu \mathrm{M}$ of A3227 or vehicle for $5 \mathrm{~min}$. The reaction was terminated by the addition of an ice-cold EDTA (10 $\mathrm{mM}$ ) solution. The black line indicates the percentage of transmittance of each sample (isolated platelets recorded as $0 \%$, and PPP recorded as 100\%). The blue line indicates small aggregates (9-25 $\mu \mathrm{m})$; green line, medium aggregates $(25-50 \mu \mathrm{m})$; and red line, large aggregates (50-70 $\mu \mathrm{m})$. The lower panel presents the distribution (\%) of aggregated particle size as measured by laser scattering. Representative results obtained from five individuals are shown.

Table 1. Effects of NSC23766 on the aggregation of human platelets induced by SCP0237 and A3227. PRP was pretreated with $70 \mu \mathrm{M}$ of NSC23766 or vehicle at $37^{\circ} \mathrm{C}$ for $15 \mathrm{~min}$, and then stimulated by $7 \mu \mathrm{M}$ of SCP0237 or $70 \mu \mathrm{M}$ of A3227 for $5 \mathrm{~min}$. The reaction was terminated by the addition of an ice-cold EDTA $(10 \mathrm{mM})$ solution. The results obtained from the aggregometer with laser scattering for the transmittance and ratio of the size of platelet aggregates are summarized. Each value represents the mean \pm SEM of five individuals. ${ }^{*} \mathrm{p}<0.05$, compared with a PAR agonist without NSC23766

\begin{tabular}{lcccc}
\hline & \multicolumn{2}{c}{ SCP0237 } & \multicolumn{2}{c}{$\mathrm{A} 227$} \\
& + & + & + & + \\
\hline NSC23766 $(\mu \mathrm{M})$ & 0 & 70 & 0 & 70 \\
Transmittance $(\%)$ & $92.8 \pm 2.8$ & $47.8 \pm 6.8^{*}$ & $98.0 \pm 10.2$ & $7.5 \pm 1.4^{*}$ \\
Large $(\%)$ & $54.8 \pm 3.0$ & $30.4 \pm 9.7^{*}$ & $51.0 \pm 13.7$ & $0.3 \pm 0.3^{*}$ \\
Medium $(\%)$ & $16.4 \pm 0.5$ & $20.6 \pm 1.9$ & $17.3 \pm 1.0$ & $0.8 \pm 0.8^{*}$ \\
Small $(\%)$ & $29.2 \pm 2.5$ & $48.8 \pm 8.1^{*}$ & $31.8 \pm 12.8$ & $99.0 \pm 0.7^{*}$ \\
\hline
\end{tabular}

Effects of NSC23766 on the TRAP-induced release of phosphorylated-HSP27 from human platelets

We have previously shown that phosphorylated-HSP27 is released into plasma from TRAP-stimulated platelets of diabetic patients and is accompanied with the phosphorylation of intracellular HSP27 [32]. It is generally known that PDGF-AB, which is stored in $\alpha$-granules of human platelets, is secreted into plasma from activated platelets [36]. Therefore, we investigated the role of Rac in the TRAP-elicited release of phosphorylated-HSP27 compared 


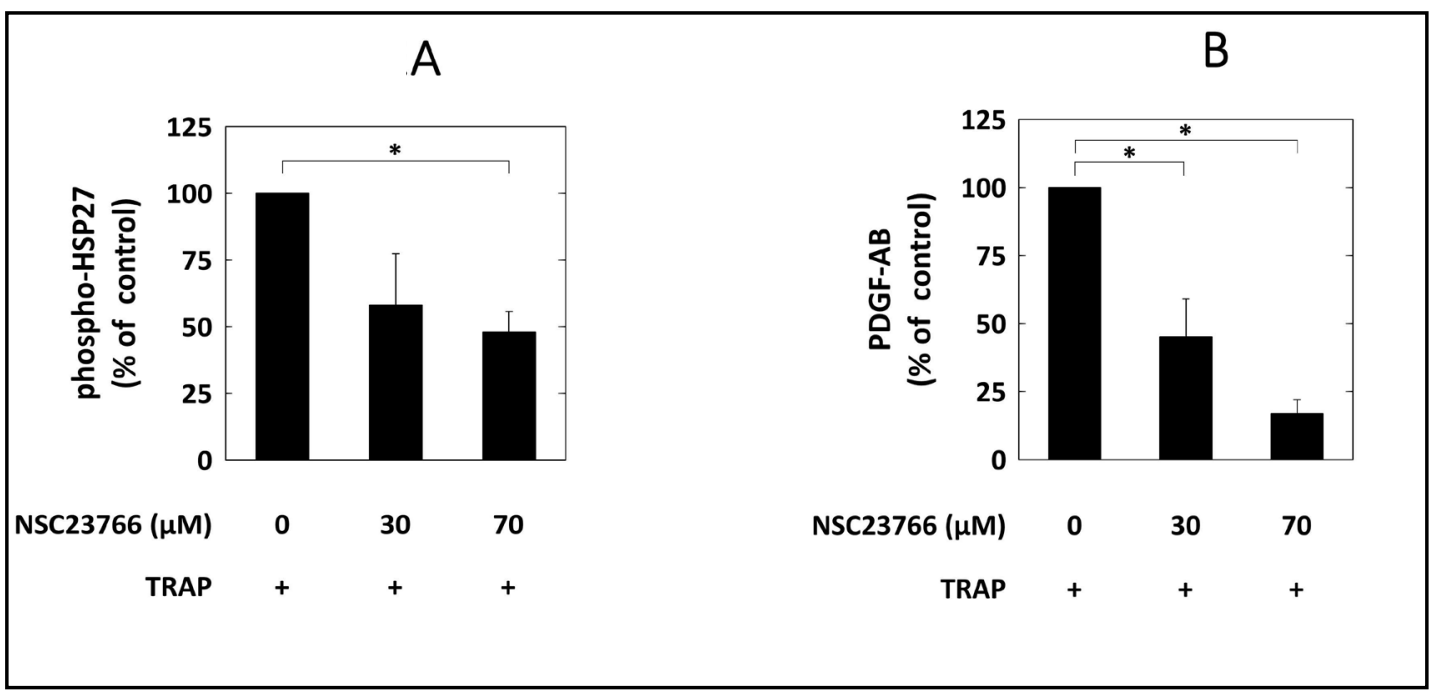

Fig. 2. Effect of NSC23766 on the TRAP-induced release of phosphorylated-HSP27 from human platelets compared with the secretion of PDGF-AB. PRP was pretreated with the indicated doses of NSC23766 or vehicle at $37^{\circ} \mathrm{C}$ for $15 \mathrm{~min}$, and then stimulated by TRAP for $5 \mathrm{~min}$. The dose of TRAP achieving a transmittance of $80-100 \%$ recorded using a PA-200 aggregometer was adjusted individually. The reaction was terminated by the addition of an ice-cold EDTA (10 mM) solution. The conditioned mixture was centrifuged at 10,000 $\times$ $\mathrm{g}$ at $4^{\circ} \mathrm{C}$ for $2 \mathrm{~min}$, and the supernatant was then subjected to ELISA for phosphorylated-HSP27 (A) or PDGF$\mathrm{AB}(\mathrm{B})$. The increased levels by TRAP alone are represented as $100 \%$. The results from five individuals are shown. Each value represents the mean \pm SEM. ${ }^{*} \mathrm{p}<0.05$, compared with TRAP alone.

with PDGF-AB secretion. The release of phosphorylated-HSP27 was reduced by NSC23766 in a dose-dependent manner over the range of $30 \mu \mathrm{M}$ to $70 \mu \mathrm{M}$, and $70 \mu \mathrm{M}$ of NSC23766 caused an approximately 50\% reduction in its release compared with TRAP stimulation alone (Fig. 2A). Similarly, PDGF-AB secretion was suppressed by NSC23766 in a dosedependent manner, and $70 \mu \mathrm{M}$ of NSC23766 caused an approximately $80 \%$ reduction in the effect of TRAP (Fig. 2B).

We examined the effects of NSC23766 on the release of phosphorylated-HSP27 from human platelets by a PAR1 or PAR4 agonist. NSC23766 significantly reduced the SCP0237induced release of phosphorylated-HSP27 (Fig. 3A) as well as the secretion of PDGF-AB (Fig. 3B). In addition, NSC23766 remarkably suppressed the A3227-stimulated release of phosphorylated-HSP27 (Fig. 3C) and secretion of PDGF-AB (Fig. 3D).

Effect of NSC23766 on the TRAP-induced phosphorylation of HSP27 in human platelets

We next investigated the effect of TRAP on the phosphorylation of HSP27 in human platelets. TRAP truly induced HSP2 7 phosphorylation in human platelets, and the maximum levels of phosphorylated-HSP27 were observed during 30-90 s after stimulation, and its levels declined thereafter (Fig. 4A and 4B). NSC23766 significantly attenuated the TRAPinduced HSP27 phosphorylation in human platelets (Fig. 5).

Effects of TRAP on the phosphorylation of p38 MAPK, p44/p42 MAPK, JNK and Akt in human platelets

It has been reported that Rac has a role in the activation of Akt, JNK and p38 MAPK [37]. Regarding HSP27 phosphorylation in human platelets, we previously showed that Rac postitively regulates collagen-induced HSP27 phosphorylation at a point upstream of p44/ p42 MAPK [30]. In addition, we demonstrated that the TRAP-stimulated activation of Akt is involved in the phosphorylation of HSP27 and its subsequent release in diabetic patients [32]. Thus, we next examined the effects of TRAP on the phosphorylation of p38 MAPK, $\mathrm{p} 44 / \mathrm{p} 42$ MAPK, JNK and Akt using platelets from healthy volunteers. The maximum levels 
Fig. 3. Effects of NSC23766 on the release of phosphorylated-HSP27 induced by SCP0237 and A3227 from human platelets compared with the secretion of PDGF-AB. PRP was pretreated with 70 $\mu \mathrm{M}$ of NSC23766 or vehicle at $37^{\circ} \mathrm{C}$ for $15 \mathrm{~min}$, and then stimulated by $7 \mu \mathrm{M}$ of SCP0237 (A, B), $70 \mu \mathrm{M}$ of A3227 (C, D) or vehicle for $5 \mathrm{~min}$. The reaction was terminated by the addition of an ice-cold EDTA (10 mM) solution. The conditioned mixture was centrifuged at $10,000 \times \mathrm{g}$ at $4^{\circ} \mathrm{C}$ for $2 \mathrm{~min}$, and the supernatant was then subjected to ELISA for phosphorylated-HSP27 (A, C) or PDGF-AB (B, D). The results from four $(A, B)$ or three (C, D) individuals are shown. Each value represents the mean \pm SEM. ${ }^{*} \mathrm{p}<0.05$, compared with SCP0237 (A, B) or A3227 (C, D) alone.

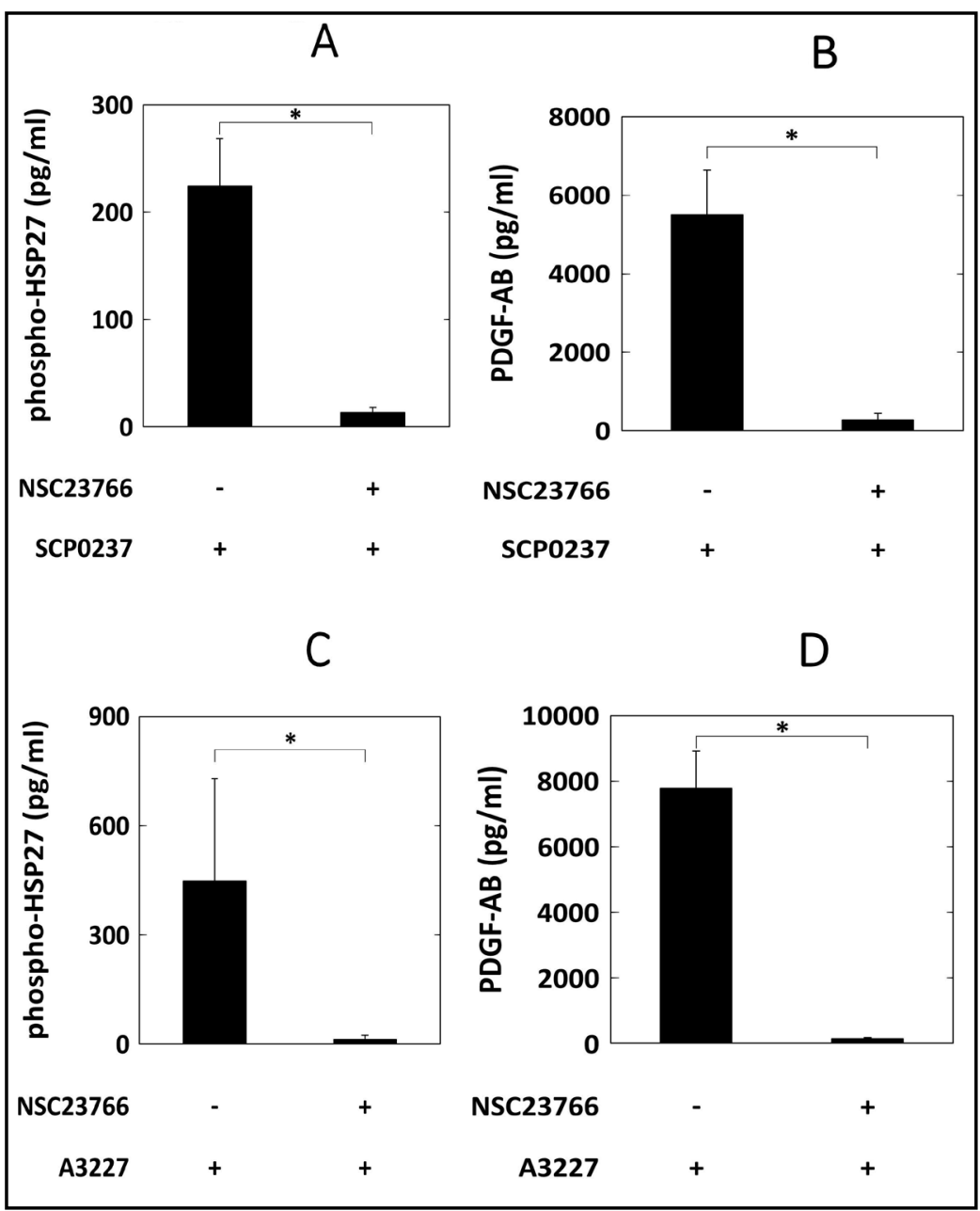

\section{A}

B
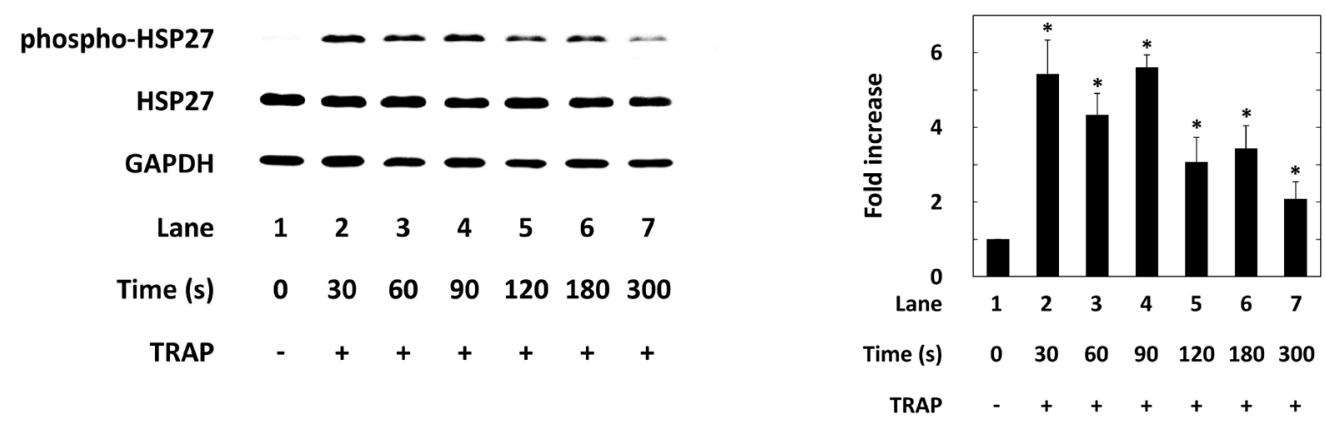

Fig. 4. Effect of TRAP on the phosphorylation of HSP27 in human platelets. PRP was stimulated by $12 \mu \mathrm{M}$ of TRAP at $37^{\circ} \mathrm{C}$ for the indicated periods. The reaction was terminated by the addition of an ice-cold EDTA (10 $\mathrm{mM}$ ) solution. The lysed platelets were subjected to Western blot analysis using antibodies against phosphospecific HSP27, HSP27 and GAPDH. (A) Representative results of Western blot analysis are presented. (B) The histogram shows a quantitative representation of the TRAP-induced phosphorylation levels obtained from laser densitometric analysis of three independent experiments. Phosphorylation is expressed as a fold increase compared to the basal levels, presented as lane 1. Each value was corrected by the level of GAPDH and represents the mean \pm SEM. ${ }^{*} \mathrm{p}<0.05$, compared with control. 


\section{Cellular Physiology Cell Physiol Biochem 2018;49:1523-1538 and Biochemistry \begin{tabular}{l|l} 
DOI: 10.1159/000493456 & $\begin{array}{l}\text { O } 2018 \text { The Author(s). Published by S. Karger AG, Basel } \\
\text { wwww.karger.com/cpb }\end{array}$
\end{tabular}

Fig. 5. Effect of NSC23766 on the TRAP-induced phosphorylation of HSP27 in human platelets. PRP was pretreated with $70 \mu \mathrm{M}$ of NSC23766 or vehicle at $37^{\circ} \mathrm{C}$ for $15 \mathrm{~min}$, and then stimulated by TRAP or vehicle for $90 \mathrm{~s}$. The dose of TRAP achieving a transmittance of $80-100 \%$ recorded using a PA-200 aggregometer was adjusted individually. The reaction was terminated by the addition of an ice-cold EDTA (10 mM) solution. The lysed platelets were subjected to Western blot analysis using antibodies against phosphospecific HSP27, HSP27 and GAPDH. The histogram shows a quantitative representation of the TRAPinduced phosphorylation levels obtained from laser densitometric analysis of three independent experiments. Phosphorylation is expressed as a fold increase compared to the basal levels, presented as lane 1. Each value was corrected by the level of GAPDH and represents the mean \pm SEM. ${ }^{*} \mathrm{p}<0.05$, compared with control. ${ }^{* *} \mathrm{p}<0.05$ compared with TRAP alone.

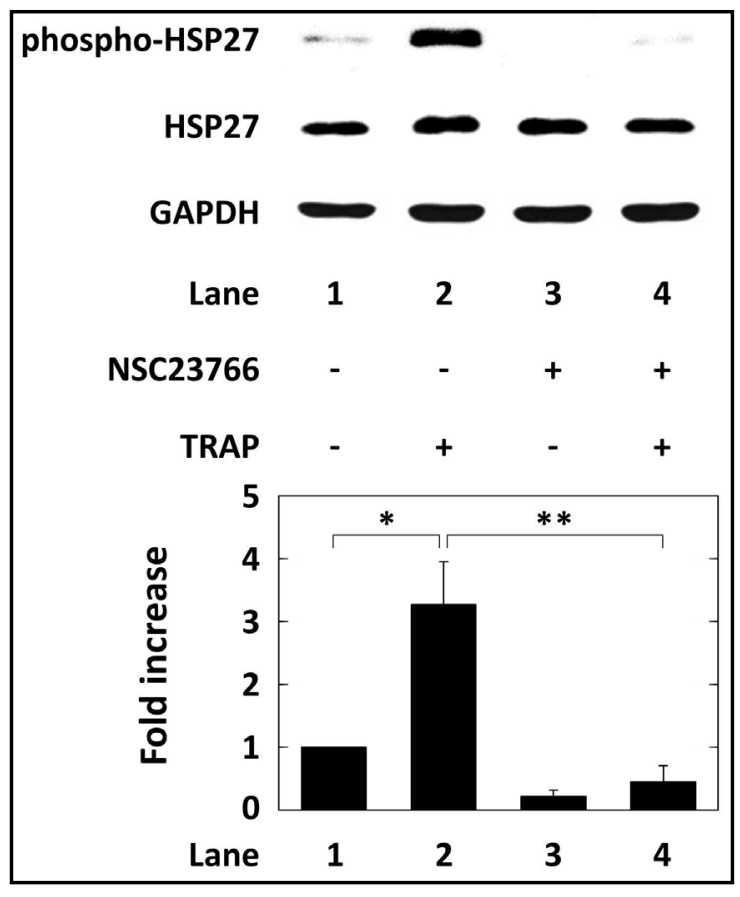

of phosphorylated-p38 MAPK were observed during 60-90 s after TRAP stimulation, and its levels decreased thereafter (Fig. 6A and 6C). On the other hand, the levels of phosphorylatedJNK increased continuously for up to $300 \mathrm{~s}$ after stimulation (Fig. 6A and 6D). In contrast, TRAP had little effect on the phosphorylation of p44/p42 MAPK and Akt (Fig. 6A, 6B and 6E).

Effects of NSC23766 on the TRAP-induced phosphorylation of p38 MAPK and JNK in human platelets

In order to clarify whether Rac plays a role in the TRAP-induced activation of p38 MAPK and JNK in human platelets, we examined the effects of NSC23766 on the TRAP-induced phosphorylation of p38 MAPK and JNK. NSC23766 markedly decreased the levels of TRAPinduced phosphorylated-p38 MAPK (Fig. 7A). Additionally, JNK phosphorylation induced by TRAP was significantly reduced by NSC23766 (Fig. 7B).

Effects of SB203580 and SP600125 on the TRAP-induced phosphorylation of HSP27 in human platelets

To elucidate whetherp38MAPKandJNKareinvolved in the TRAP-elicited phosphorylation of HSP27 in human platelets, we examined the effects of SB203580, a p38 MAPK inhibitor [38], and SP600125, a JNK inhibitor [39], on HSP27 phosphorylation. SB203580 significantly inhibited the phosphorylation of HSP27 by TRAP (Fig. 8A). Conversely, SP600125 had little effect on the TRAP-induced phosphorylation of HSP27 (Fig. 8B).

Effects of SB203580 and SP600125 on the TRAP-induced release of phosphorylated-HSP27 from human platelets

We additionally examined the effects of SB203580 and SP600125 on the TRAP-induced release of phosphorylated-HSP27 from human platelets compared with the secretion of PDGF-AB. SB203580 but not SP600125 significantly reduced the TRAP-induced release of phosphorylated-HSP27 from human platelets (Table 2). On the other hand, both SB203580 and SP600125 markedly inhibited the TRAP-induced secretion of PDGF-AB from human platelets (Table 2).

Furthermore, we investigated the role of JNK on the release of phosphorylated-HSP27 and secretion of PDGF-AB following PAR activation in human platelets. SP600125 failed to inhibit the release of phosphorylated-HSP27 induced by SCP0237 and A3227 (Table 3). In 


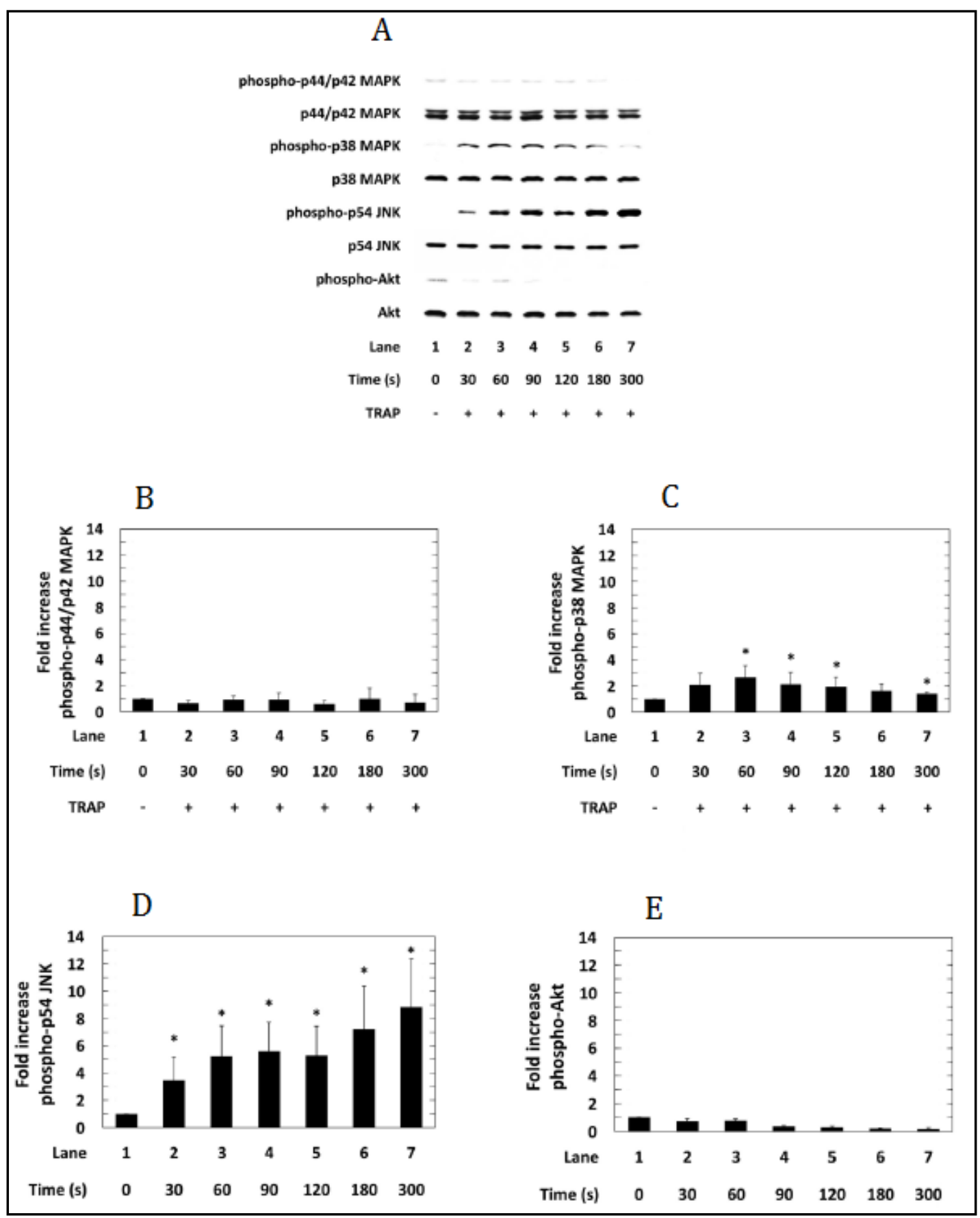

Fig. 6. Effects of TRAP on the phosphorylation of p44/p42 MAPK, p38 MAPK, JNK and Akt in human platelets. PRP was stimulated by $12 \mu \mathrm{M}$ of TRAP at $37^{\circ} \mathrm{C}$ for the indicated periods. The reaction was terminated by the addition of an ice-cold EDTA $(10 \mathrm{mM})$ solution. The lysed platelets were subjected to Western blot analysis using antibodies against phospho-specific p38 MAPK, p38 MAPK, phospho-specific p44/p42 MAPK, p44/p42 MAPK, phospho-specific JNK (p54), JNK (p54), phospho-specific Akt, Akt and GAPDH. (A) Representative results of Western blot analysis are presented. The histogram shows a quantitative representation of the TRAP-induced phosphorylation levels of p44/p42 MAPK (B), p38 MAPK (C), p54 JNK (D) and Akt (E) obtained from laser densitometric analysis of three independent experiments. Phosphorylation is expressed as a fold increase compared to the basal levels, presented as lane 1. Each value was corrected by the respective level of total protein and represents the mean \pm SEM. ${ }^{*} \mathrm{p}<0.05$, compared with control. 


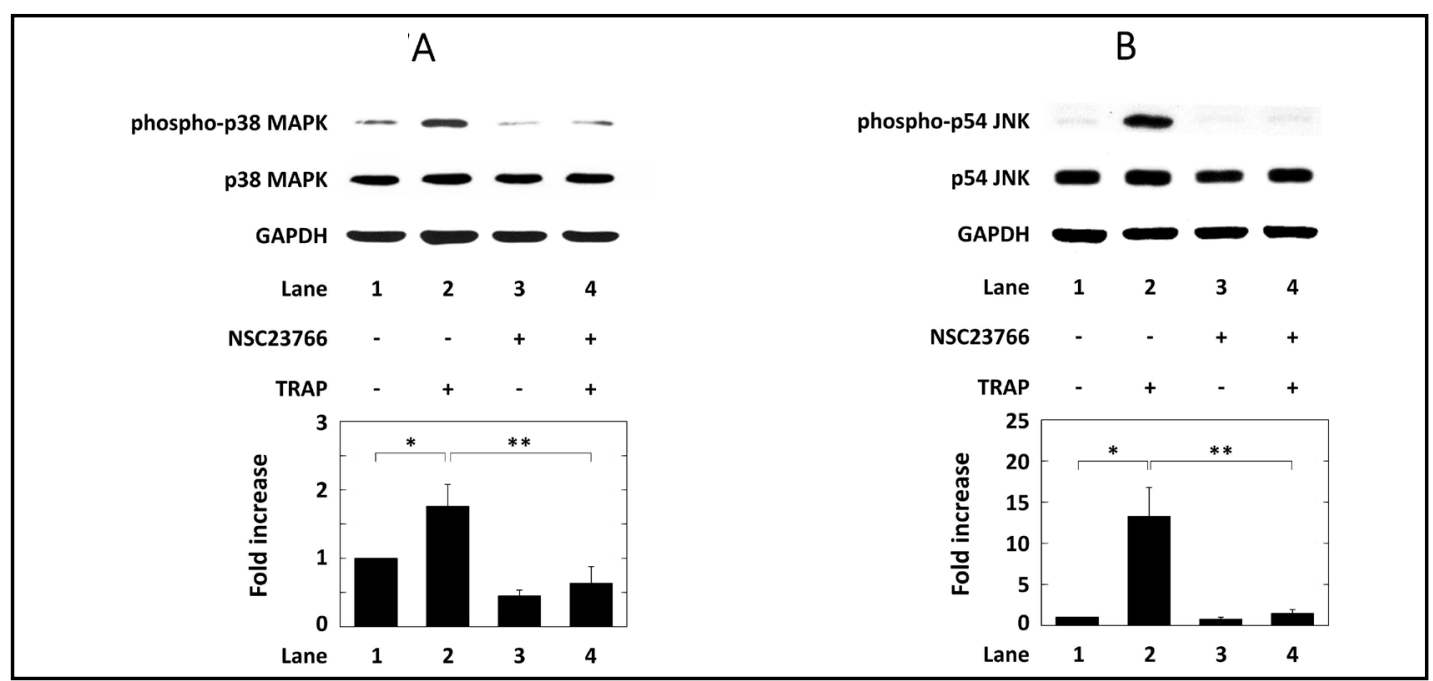

Fig. 7. Effects of NSC23766 on the TRAP-induced phosphorylation of p38 MAPK (A) and JNK (B) in human platelets. PRP was pretreated with $70 \mu \mathrm{M}$ of NSC23766 or vehicle at $37^{\circ} \mathrm{C}$ for $15 \mathrm{~min}$, and then stimulated by TRAP or vehicle for $60 \mathrm{~s}$. The dose of TRAP achieving a transmittance of $80-100 \%$ recorded using a PA-200 aggregometer was adjusted individually. The reaction was terminated by the addition of an icecold EDTA (10 mM) solution. The lysed platelets were subjected to Western blot analysis using antibodies against phospho-specific p38 MAPK, p38 MAPK, phospho-specific JNK (p54), JNK (p54) and GAPDH. The histogram shows a quantitative representation of the TRAP-induced phosphorylation levels obtained from laser densitometric analysis of three independent experiments. Phosphorylation is expressed as a fold increase compared to the basal levels, presented as lane 1. Each value was corrected by the level of GAPDH and represents the mean \pm SEM. ${ }^{*} \mathrm{p}<0.05$, compared with control. ${ }^{* *} \mathrm{p}<0.05$, compared with TRAP alone.

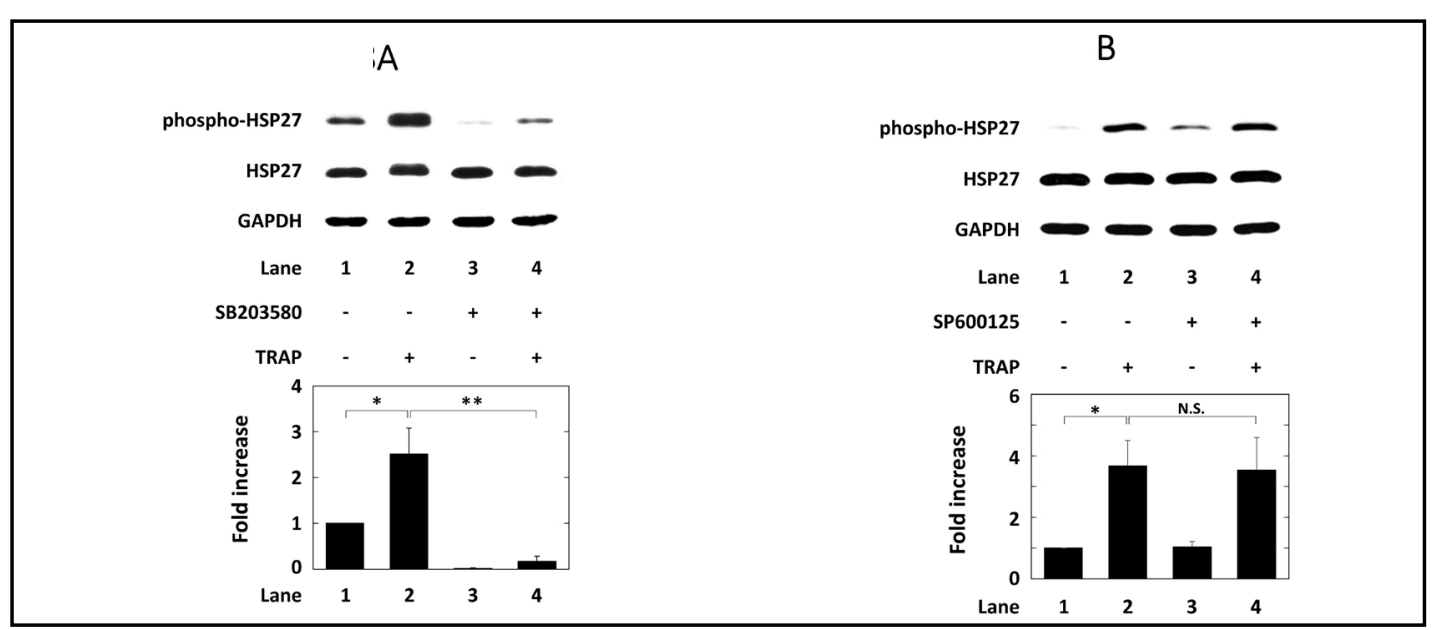

Fig. 8. Effects of SB203580 (A) and SP600125 (B) on the TRAP-induced phosphorylation of HSP27 in human platelets. PRP was pretreated with $30 \mu \mathrm{M}$ of SB203580, $10 \mu \mathrm{M}$ of SP600125 or vehicle at $37^{\circ} \mathrm{C}$ for $15 \mathrm{~min}$, and then stimulated by TRAP or vehicle for $60 \mathrm{~s}$. The dose of TRAP achieving a transmittance of 80-100\% recorded using a PA-200 aggregometer was adjusted individually. The reaction was terminated by the addition of an ice-cold EDTA $(10 \mathrm{mM})$ solution. The lysed platelets were subjected to Western blot analysis using antibodies against phospho-specific HSP27, HSP27 and GAPDH. The histogram shows a quantitative representation of the TRAP-induced phosphorylation levels obtained from laser densitometric analysis of three independent experiments. Phosphorylation is expressed as a fold increase compared to the basal levels, presented as lane 1. Each value was corrected by the level of GAPDH and represents the mean \pm SEM. ${ }^{*} \mathrm{p}<0.05$, compared with control. ${ }^{* *} \mathrm{p}<0.05$, compared with TRAP alone. N.S. designates no significant difference between the indicated pairs. 
Table 2. Effects of SB203580 and SP600125 on the TRAP-induced release of phosphorylated-HSP27 from human platelets compared with the secretion of PDGF-AB. PRP was pretreated with $30 \mu \mathrm{M}$ of SB203580, 10 $\mu \mathrm{M}$ of SP 600125 or vehicle at $37^{\circ} \mathrm{C}$ for $15 \mathrm{~min}$, and then stimulated by TRAP for $5 \mathrm{~min}$. The dose of TRAP achieving a transmittance of $80-100 \%$ recorded using a PA-200 aggregometer was adjusted individually. The reaction was terminated by the addition of an ice-cold EDTA $(10 \mathrm{mM})$ solution. The conditioned mixture was centrifuged at $10,000 \times \mathrm{g}$ at $4^{\circ} \mathrm{C}$ for $2 \mathrm{~min}$, and the supernatant was then subjected to ELISA for phosphorylated-HSP27 or PDGF-AB. The results from five individuals are shown. Each value represents the mean \pm SEM of net increase from baseline. ${ }^{*} \mathrm{p}<0.05$, compared with TRAP stimulation alone. N.S. designates no significant difference compared with TRAP stimulation alone

\begin{tabular}{lccr}
\hline & & phosphorylated-HSP27 $(\mathrm{pg} / \mathrm{ml})$ & PDGF-AB $(\mathrm{pg} / \mathrm{ml})$ \\
\hline- & TRAP & $112.0 \pm 41.5$ & $4029.6 \pm 383.3$ \\
SB203580 & TRAP & $22.1 \pm 17.9^{*}$ & $930.9 \pm 238.5^{*}$ \\
SP600125 & TRAP & $114.3 \pm 22.5^{\text {N.S. }}$ & $2661.3 \pm 426.6^{*}$ \\
\hline
\end{tabular}

Table 3. Effects of SP 600125 on the release of phosphorylated-HSP 27 induced by SCP0237 and A3227 from human platelets compared with the secretion of PDGF-AB. PRP was pretreated with $10 \mu \mathrm{M}$ of SP 600125 or vehicle at $37^{\circ} \mathrm{C}$ for $15 \mathrm{~min}$, and then stimulated by $7 \mu \mathrm{M}$ of SCP0237 or $70 \mu \mathrm{M}$ of A3227 for 5 $\mathrm{min}$. The reaction was terminated by the addition of an ice-cold EDTA $(10 \mathrm{mM})$ solution. The conditioned mixture was centrifuged at $10,000 \times \mathrm{g}$ at $4^{\circ} \mathrm{C}$ for $2 \mathrm{~min}$, and the supernatant was then subjected to ELISA for phosphorylated-HSP27 or PDGF-AB. The results from three individuals are shown. Each value represents the mean \pm SEM of net increase from baseline. ${ }^{*} \mathrm{p}<0.05$, compared with a PAR agonist alone

\begin{tabular}{lccr}
\hline & & phosphorylated-HSP27 (pg/ml) & PDGF-AB (pg/ml) \\
\hline- & SCP0237 & $171.7 \pm 55.2$ & $3936.7 \pm 149.7$ \\
SP600125 & SCP0237 & $212.7 \pm 89.2$ & $3014.7 \pm 189.2^{*}$ \\
- & A3227 & $97.9 \pm 26.6$ & $2294.6 \pm 124.2$ \\
SP600125 & A3227 & $125.7 \pm 60.0$ & $1608.7 \pm 193.0^{*}$ \\
\hline
\end{tabular}

contrast, the secretion of PDGF-AB induced by SCP0237 and A3227 was significantly reduced by SP600125 (Table 3).

\section{Discussion}

In the present study, we investigated the role of Rac in the PAR-induced release of phosphorylated-HSP27 from human platelets compared with the secretion of PDGF-AB. It is recognized that TRAP possesses an identical amino acid sequence to the tethered ligand of PARs cleaved by thrombin, and acts as a selective PAR agonist [9]. Initially, we confirmed that Rac was truly activated by PAR stimulation based on the finding of the TRAPinduced increase of GTP-binding Rac in human platelets, which is in accordance with a previous report [15]. We also found that NSC23766 [2] suppressed TRAP-induced platelet aggregation, suggesting that Rac is involved in PAR-induced platelet aggregation in human platelets. On the basis of our previous report showing that TRAP-activated human platelets release phosphorylated-HSP27 due to its phosphorylation [32], we investigated the role of Rac in the release of phosphorylated-HSP27. NSC23766 significantly suppressed the release of phosphorylated-HSP27 by TRAP from human platelets, suggesting that Rac regulates the PAR-induced release of phosphorylated-HSP27. To the best of our knowledge, this is probably the first report showing the involvement of Rac in the PAR-induced release of phosphorylated-HSP27 from human platelets. In addition, we demonstrated that TRAP truly induced the phosphorylation of HSP27 in human platelets, and that NSC23766 significantly suppressed this phosphorylation. Therefore, it is most likely that Rac positively regulates the PAR-induced phosphorylation of HSP27 in human platelets, resulting in the release of phosphorylated-HSP27. Regarding PARs, it has been shown that human platelets express PAR1 and PAR4 [8]. In the present study, we clearly showed that NSC23766 suppressed 


\section{Cellular Physiology Cell Physiol Biochem 2018;49:1523-1538

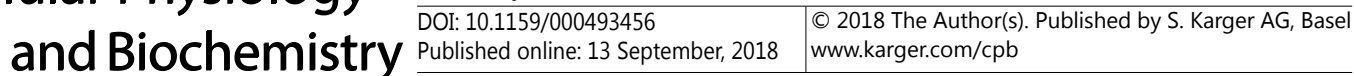 \\ Uematsu et al.: Rac Regulates the Release of Phospho-HSP27}

the aggregation of human platelets induced by both SCP0237, a selective PAR1 agonist [34], and A3227, a selective PAR4 agonist [35]. Furthermore, NSC23766 markedly reduced the release of phosphorylated-HSP27 as well as the secretion of PDGF-AB [36] induced by these PAR agonists. Taking these findings into account, it is most likely that Rac functions as a downstream signaling molecule of both PAR1 and PAR4 in human platelets, leading to HSP27 phosphorylation and its subsequent release.

Regarding the Rac signaling pathway, it has been reported that Rac activation is related to Akt, JNK and p38 MAPK [32, 37]. We have previously shown that Rac positively regulates collagen-induced human platelet activation via p44/p42 MAPK [30]. Thus, we investigated whether PAR activation could induce the activation of these intracellular molecules in human platelets. TRAP truly elicited the phosphorylation of p38 MAPK and JNK without affecting the phosphorylation of p44/p42 MAPK or Akt. In addition, we showed that NSC23766 actually attenuated the TRAP-induced phosphorylation of both p38 MAPK and JNK. Therefore, it seems likely that Rac acts as an upstream regulator of both p38 MAPK and JNK in the PARinduced signaling pathway in human platelets. Regarding the kinetics of the TRAP-induced phosphorylation of JNK and p38 MAPK, the peak of p38 MAPK phosphorylation was observed at 60-90 s after stimulation, whereas that of JNK was detected after $300 \mathrm{~s}$. Thus, it is possible that since some intracellular signaling molecules may exist between Rac1 and JNK in the TRAP signaling pathway in human platelets, the kinetics of the TRAP-induced phosphorylation of JNK and p38 MAPK are different. We further demonstrated that SB203580 [38] but not SP600125 [39] inhibited TRAP-induced HSP27 phosphorylation in human platelets. It seems that p38 MAPK but not JNK is involved in the phosphorylation of HSP27 by TRAP. The p38 MAPK family consists of four isoforms named p38 $\alpha, p 38 \beta, p 38 \gamma$ and p38 [40], and it has been shown that all four isoforms are expressed in human platelets [41]. SB203580 reportedly inhibits $\mathrm{p} 38 \alpha$ and $\mathrm{p} 38 \beta$, but not $\mathrm{p} 38 \gamma$ and $\mathrm{p} 38 \delta$ [42]. Therefore, it is probable that p38 $\gamma$ and p38 $\delta$ may not be involved in the PAR-Rac-phosphorylated-HSP27 release pathway. On the basis of our present findings, it is most likely that the phosphorylation of HSP27 induced by TRAP is mediated through the activation of $\mathrm{p} 38 \alpha / \beta$ MAPK but not JNK in human platelets. We also demonstrated that SB203580 but not SP600125 suppressed the TRAP-

Fig. 9. Diagram of the potential mechanism underlying the role of Rac in the TRAP-induced release of phosphorylated-HSP27 from human platelets compared with PDGF-AB secretion. PAR, proteaseactivated receptor; MAPK, mitogen-activated protein kinase; JNK, c-Jun N-terminal kinase; HSP, heat shock protein; PDGF-AB, platelet-derived growth factor-AB; P, phosphorylation.

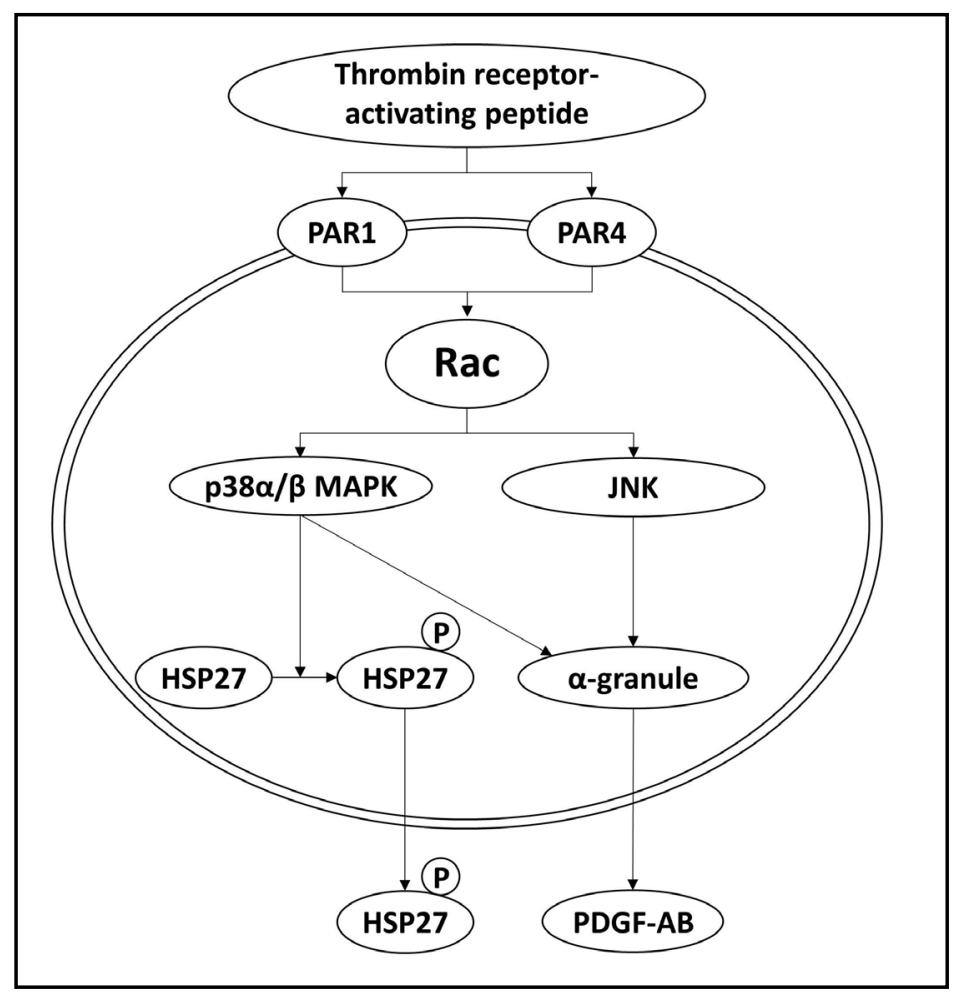




\section{Cellular Physiology Cell Physiol Biochem 2018;49:1523-1538 \begin{tabular}{l|l} 
DOI: 10.1159/000493456 & $\begin{array}{l}\text { O } 2018 \text { The Author(s). Published by S. Karger AG, Basel } \\
\text { www.karger.com/cpb }\end{array}$
\end{tabular} \\ Uematsu et al.: Rac Regulates the Release of Phospho-HSP27}

induced release of phosphorylated-HSP27 from human platelets, suggesting that $\mathrm{p} 38 \alpha / \beta$ MAPK but not JNK regulates the phoshorylation of HSP27. In contrast with the release of phosphorylated-HSP27, the TRAP-induced secretion of PDGF-AB from human platelets was suppressed by both SB203580 and SP600125. Furthermore, we showed that SP600125, which inhibited the secretion of PDGF-AB induced by SCP0237 and A3227, failed to suppress the release of phosphorylated-HSP27. Therefore, it seems likely that JNK regulates the PARinduced secretion of PDGF-AB but not the release of phosphorylated-HSP27. Taking our findings into account as a whole, our results strongly suggest that, in TRAP-activated human platelets, Rac functions as a positive regulator of the phosphorylation of HSP27 through $\mathrm{p} 38 \alpha / \beta$ MAPK but not JNK, resulting in the release of phosphorylated-HSP27. The potential mechanism underlying the role of Rac in the PAR-induced release of phosphorylated-HSP27 from human platelets compared with the secretion of PDGF-AB is summarized in Fig. 9.

Although HSP27 has been recognized to be present inside cells and act as a molecular chaperone, accumulating evidence indicates that HSP27 also has extracellular functions $[25,43]$. It has been shown that extracellular HSP27 upregulates pro-inflammatory factors such as IL-1 $\beta$ in macrophages [27]. In addition, HSP27 released from ischemic myocardium reportedly induces a pro-inflammatory response in human coronary vascular endothelium [44]. Since it is firmly established that inflammation is a potent promotor of atherosclerosis [36], it is probable that extracellular HSP27 affects the development of atherosclerosis. Regarding HSP27 in human platelets, we have previously reported that TRAP stimulates the release of phosphorylated-HSP27 via the activation of Akt in addition to p38 MAPK from platelets in diabetic patients [32]. In the present study, we showed that p38 MAPK but not Akt is involved in the release of phosphorylated-HSP27 stimulated by TRAP from the platelets of healthy volunteers. It seems likely that the mechanism of HSP27 phosphorylation in platelets is quite different between diabetic patients and healthy volunteers. The activation of Akt stimulated by TRAP in platelets is possibly a pathological event, providing a new viewpoint with respect to the increased risk of atherosclerosis in patients with diabetes. In addition, based on our present findings showing that PAR-induced Rac activation positively regulates HSP27 release from human platelets as well as platelet aggregation, the regulation of Rac in platelets may represent a novel therapeutic strategy for atherosclerotic and/or thrombotic diseases such as acute coronary syndrome or brain stroke. Indeed, NSC23766 is expected to be applied clinically for the treatment of cardiovascular and cerebrovascular diseases [45]. On the other hand, it has recently been reported that extracellular HSP27 also possesses anti-inflammatory functions, suggesting that HSP27 is protective against the development of atherosclerosis [25]. Further investigations are required to clarify the exact roles of extracellular HSP27.

\section{Conclusion}

Taken together, our present findings strongly suggest that Rac acts as a positive regulator of the PAR-elicited release of phosphorylated-HSP27 via p38 MAPK but not JNK from human platelets.

\section{Disclosure Statement}

All authors declare that we have no conflicts of interest in connection with this paper. 


\section{Cellular Physiology Cell Physiol Biochem 2018;49:1523-1538 \begin{tabular}{ll|l} 
and Biochemistry Published online: 13 September, 2018 & $\begin{array}{l}\text { (c) } 2018 \text { The Author(s). Published by S. Karger AG, Basel } \\
\text { www.karger.com/cpb }\end{array}$ \\
\hline
\end{tabular}}

Uematsu et al.: Rac Regulates the Release of Phospho-HSP27

\section{Acknowledgements}

We thank Yumiko Kurokawa for her skillful technical assistance. This investigation was supported in part by a Research Funding for Longevity Science (28-9) from National Center for Geriatrics and Gerontology, Japan.

\section{References}

1 Takai Y, Sasaki T, Matozaki T: Small GTP-binding proteins. Physiol Rev 2001;81:153-208.

2 Gao Y, Dickerson JB, Guo F, Zheng J, Zheng Y: Rational design and characterization of a Rac GTPase-specific small molecule inhibitor. Proc Natl Acad Sci U S A 2004;101:7618-7623.

-3 Heasman SJ, Ridley AJ: Mammalian Rho GTPases: new insights into their functions from in vivo studies. Nat Rev Mol Cell Biol 2008;9:690-701.

4 Aslan JE, McCarty OJ: Rho GTPases in platelet function. J Thromb Haemost 2013;11:35-46.

5 Ridley AJ: Rho GTPase signalling in cell migration. Curr Opin Cell Biol 2015;36:103-112.

6 Furie B, Furie BC: Mechanisms of thrombus formation. N Engl J Med 2008;359:938-949.

7 Coughlin SR: How the protease thrombin talks to cells. Proc Natl Acad Sci U S A 1999;96:11023-11027.

8 Duvernay MT, Temple KJ, Maeng JG, Blobaum AL, Stauffer SR, Lindsley CW, Hamm HE: Contributions of protease-activated receptors PAR1 and PAR4 to thrombin-induced GPIIbIIIa activation in human platelets. Mol Pharmacol 2017;91:39-47.

-9 Aoki T, Tomiyama Y, Honda S, Senzaki K, Tanaka A, Okubo M, Takahashi F, Takasugi H, Seki J: Difference of $\left[\mathrm{Ca}^{2+}\right]$ movements in platelets stimulated by thrombin and TRAP: the involvement of $\alpha_{\mathrm{IIb}} \beta_{3}$-mediated TXA synthesis. Thromb Haemost 1998;79:1184-1190.

10 Pleines I, Elvers M, Strehl A, Pozgajova M, Varga-Szabo D, May F, Chrostek-Grashoff A, Brakebusch C, Nieswandt B: Rac1 is essential for phospholipase $\mathrm{C}-\gamma 2$ activation in platelets. Pflugers Arch 2009;457:1173-1185.

11 Akbar H, Kim J, Funk K, Cancelas JA, Shang X, Chen L, Johnson JF, Williams DA, Zheng Y: Genetic and pharmacologic evidence that Rac1 GTPase is involved in regulation of platelet secretion and aggregation. J Thromb Haemost 2007;5:1747-1755.

12 Pandey D, Goyal P, Dwivedi S, Siess W: Unraveling a novel Rac1-mediated signaling pathway that regulates cofilin dephosphorylation and secretion in thrombin-stimulated platelets. Blood 2009;114:415-424.

13 McCarty OJ, Larson MK, Auger JM, Kalia N, Atkinson BT, Pearce AC, Ruf S, Henderson RB, Tybulewicz VL, Machesky LM, Watson SP: Rac1 is essential for platelet lamellipodia formation and aggregate stability under flow. J Biol Chem 2005;280:39474-39484.

14 Kageyama Y, Doi T, Matsushima-Nishiwaki R, Iida Y, Akamatsu S, Kondo A, Kuroyanagi G, Yamamoto N, Mizutani J, Otsuka T, Tokuda H, Iida H, Kozawa O, Ogura S: Involvement of Rac in thromboxane $\mathrm{A}_{2}$-induced human platelet activation: regulation of sCD40 ligand release and PDGF-AB secretion. Mol Med Rep 2014;10:107-112.

15 Soulet C, Gendreau S, Missy K, Benard V, Plantavid M, Payrastre B: Characterisation of Rac activation in thrombin- and collagen-stimulated human blood platelets. FEBS Lett 2001;507:253-258.

-16 Azim AC, Barkalow K, Chou J, Hartwig JH: Activation of the small GTPases, rac and cdc42, after ligation of the platelet PAR-1 receptor. Blood 2000;95:959-964.

17 Benjamin IJ, McMillan DR: Stress (heat shock) proteins: molecular chaperones in cardiovascular biology and disease. Circ Res 1998;83:117-132.

18 Bakthisaran R, Tangirala R, Rao Ch M: Small heat shock proteins: role in cellular functions and pathology. Biochim Biophys Acta 2015;1854:291-319.

19 Mymrikov EV, Seit-Nebi AS, Gusev NB: Large potentials of small heat shock proteins. Physiol Rev 2011;91:1123-1159.

20 Landry J, Lambert H, Zhou M, Lavoie JN, Hickey E, Weber LA, Anderson CW: Human HSP27 is phosphorylated at serines 78 and 82 by heat shock and mitogen-activated kinases that recognize the same amino acid motif as S6 kinase II. J Biol Chem 1992;267:794-803.

-21 Acunzo J, Katsogiannou M, Rocchi P: Small heat shock proteins HSP27 (HspB1), $\alpha$ B-crystallin (HspB5) and HSP22 (HspB8) as regulators of cell death. Int J Biochem Cell Biol 2012;44:1622-1631. 


\section{Cellular Physiology Cell Physiol Biochem 2018;49:1523-1538

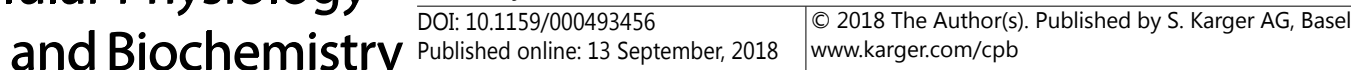

22 Kato K, Hasegawa K, Goto S, Inaguma Y: Dissociation as a result of phosphorylation of an aggregated form of the small stress protein, hsp27. J Biol Chem 1994;269:11274-11278.

23 Kostenko S, Moens U: Heat shock protein 27 phosphorylation: kinases, phosphatases, functions and pathology. Cell Mol Life Sci 2009;66:3289-3307.

24 Arrigo AP, Gibert B: HspB1, HspB5 and HspB4 in human cancers: potent oncogenic role of some of their client proteins. Cancers (Basel) 2014;6:333-365.

-25 Batulan Z, Pulakazhi Venu VK, Li Y, Koumbadinga G, Alvarez-Olmedo DG, Shi C, O’Brien ER: Extracellular release and signaling by heat shock protein 27: role in modifying vascular inflammation. Front Immunol 2016;7:285.

-26 Seibert TA, Hibbert B, Chen YX, Rayner K, Simard T, Hu T, Cuerrier CM, Zhao X, de Belleroche J, Chow BJ, Hawken S, Wilson KR, O’Brien ER: Serum heat shock protein 27 levels represent a potential therapeutic target for atherosclerosis: observations from a human cohort and treatment of female mice. J Am Coll Cardiol 2013;62:1446-1454.

27 Salari S, Seibert T, Chen YX, Hu T, Shi C, Zhao X, Cuerrier CM, Raizman JE, O’Brien ER: Extracellular HSP27 acts as a signaling molecule to activate NF- $\kappa$ B in macrophages. Cell Stress Chaperones 2013;18:53-63.

-28 Kato H, Adachi S, Doi T, Matsushima-Nishiwaki R, Minamitani C, Akamatsu S, Enomoto Y, Tokuda H, Otsuka T, Iwama T, Kozawa 0, Ogura S: Mechanism of collagen-induced release of 5-HT, PDGF-AB and sCD40L from human platelets: role of HSP27 phosphorylation via p44/p42 MAPK. Thromb Res 2010;126:39-43.

29 Kato H, Takai S, Matsushima-Nishiwaki R, Adachi S, Minamitani C, Otsuka T, Tokuda H, Akamatsu S, Doi T, Ogura S, Kozawa O: HSP27 phosphorylation is correlated with ADP-induced platelet granule secretion. Arch Biochem Biophys 2008;475:80-86.

-30 Kageyama Y, Doi T, Akamatsu S, Kuroyanagi G, Kondo A, Mizutani J, Otsuka T, Tokuda H, Kozawa O, Ogura S: Rac regulates collagen-induced HSP27 phosphorylation via p44/p42 MAP kinase in human platelets. Int J Mol Med 2013;32:813-818.

-31 Tokuda H, Kuroyanagi G, Tsujimoto M, Enomoto Y, Matsushima-Nishiwaki R, Onuma T, Kojima A, Doi T, Tanabe K, Akamatsu S, Iida H, Ogura S, Otsuka T, Iwama T, Tanikawa T, Ishikawa K, Kojima K, Kozawa O: Release of phosphorylated HSP27 (HSPB1) from platelets is accompanied with the acceleration of aggregation in diabetic patients. PLoS One 2015;10:e0128977.

32 Tokuda H, Kuroyanagi G, Tsujimoto M, Matsushima-Nishiwaki R, Akamatsu S, Enomoto Y, Iida H, Otsuka T, Ogura S, Iwama T, Kojima K, Kozawa O: Thrombin receptor-activating protein (TRAP)-activated Akt is involved in the release of phosphorylated-HSP27 (HSPB1) from platelets in DM patients. Int J Mol Sci 2016;17:737.

33 Laemmli UK: Cleavage of structural proteins during the assembly of the head of bacteriophage T4. Nature 1970;227:680-685.

34 Hollenberg MD, Saifeddine M, al-Ani B, Kawabata A: Proteinase-activated receptors: structural requirements for activity, receptor cross-reactivity, and receptor selectivity of receptor-activating peptides. Can J Physiol Pharmacol 1997;75:832-841.

-35 Hollenberg MD, Saifeddine M: Proteinase-activated receptor 4 (PAR4): activation and inhibition of rat platelet aggregation by PAR4-derived peptides. Can J Physiol Pharmacol 2001;79:439-442.

-36 Davi G, Patrono C: Platelet activation and atherothrombosis. N Engl J Med 2007;357:2482-2494.

-37 Qian F, Le Breton GC, Chen J, Deng J, Christman JW, Wu D, Ye RD: Role for the guanine nucleotide exchange factor phosphatidylinositol-3, 4,5-trisphosphate-dependent rac exchanger 1 in platelet secretion and aggregation. Arterioscler Thromb Vasc Biol 2012;32:768-777.

-38 Badger AM, Bradbeer JN, Votta B, Lee JC, Adams JL, Griswold DE: Pharmacological profile of SB 203580, a selective inhibitor of cytokine suppressive binding protein/p38 kinase, in animal models of arthritis, bone resorption, endotoxin shock and immune function. J Pharmacol Exp Ther 1996;279:1453-1461.

39 Bennett BL, Sasaki DT, Murray BW, O’Leary EC, Sakata ST, Xu W, Leisten JC, Motiwala A, Pierce S, Satoh Y, Bhagwat SS, Manning AM, Anderson DW: SP600125, an anthrapyrazolone inhibitor of Jun N-terminal kinase. Proc Natl Acad Sci U S A 2001;98:13681-13686.

40 Kyriakis JM, Avruch J: Mammalian mitogen-activated protein kinase signal transduction pathways activated by stress and inflammation. Physiol Rev 2001;81:807-869.

41 Borsch-Haubold AG, Ghomashchi F, Pasquet S, Goedert M, Cohen P, Gelb MH, Watson SP: Phosphorylation of cytosolic phospholipase $\mathrm{A}_{2}$ in platelets is mediated by multiple stress-activated protein kinase pathways. Eur J Biochem 1999;265:195-203. 


\section{Cellular Physiology Cell Physiol Biochem 2018:49:1523-1538 \begin{tabular}{l|l} 
DOI: 10.1159/000493456 & $\begin{array}{l}\text { O 2018 The Author(s). Published by S. Karger AG, Basel } \\
\text { www.karger.com/cpb }\end{array}$ \\
\hline
\end{tabular}}

Uematsu et al.: Rac Regulates the Release of Phospho-HSP27

42 Schelle I, Bruening J, Buetepage M, Genth H: Role of p38 $\alpha / \beta$ MAP kinase in cell susceptibility to Clostridium sordellii lethal toxin and Clostridium difficile toxin B. Toxins (Basel) 2016;9:pii:E2.

43 Reddy VS, Madala SK, Trinath J, Reddy GB: Extracellular small heat shock proteins: exosomal biogenesis and function. Cell Stress Chaperones 2018 May;23:441-454.

-44 Jin C, Cleveland JC, Ao L, Li J, Zeng Q Fullerton DA, Meng X: Human myocardium releases heat shock protein 27 (HSP27) after global ischemia: the proinflammatory effect of extracellular HSP27 through toll-like receptor (TLR)-2 and TLR4. Mol Med 2014;20:280-289.

45 Carrizzo A, Forte M, Lembo M, Formisano L, Puca AA, Vecchione C: Rac-1 as a new therapeutic target in cerebro- and cardio-vascular diseases. Curr Drug Targets 2014;15:1231-1246. 